\title{
Prospectiva del turismo de naturaleza en la costa de Jalisco
}

\section{A prospective analysis of nature tourism on the Jalisco coast}

José Luis Cornejo-Ortega iD, Universidad de Guadalajara, México.

jose.luiscornejo@hotmail.com

Rosa María Chávez-Dagostino, Universidad de Guadalajara, México.

rchavezdagostino@yahoo.com.mx

Rodrigo Espinoza-Sánchez, Universidad de Guadalajara, México. rikylizbe@yahoo.com.mx

\section{RESUMEN}

El sector del turismo ha jugado un papel importante en el desarrollo económico de México. El gobierno federal ha convertido al turismo en una prioridad debido al poder que tiene para mejorar las condiciones locales y generar empleos. A diferencia del turismo de sol y playa, se han señalado las posibilidades del turismo alternativo para mejorar las condiciones locales a través del empoderamiento local donde el turismo de naturaleza no ha logrado ser una estrategia totalmente exitosa para abordar los problemas de la pobreza y la marginación del medio rural, especialmente en términos de creación de empleos y generación de ingresos para las comunidades. El objetivo de esta investigación fue analizar los elementos que conforman e intervienen en el desarrollo de este sector e identificar las áreas de oportunidad. Se utilizaron métodos prospectivos para la creación de futuros posibles con las herramientas de Mic-Mac ${ }^{\circledR}$ y Smic Prob-Expert ${ }^{\circledast}$. El análisis de escenarios permitió identificar las ilustraciones en el futuro con diferentes probabilidades de ocurrencia, entre las cuales se destacó un escenario pesimista, tendencial y optimista. Se seleccionó el escenario optimista y se estableció como línea base para la ejecución del futuro del turismo de naturaleza en la costa de Jalisco.

Palabras clave: Prospectiva, turismo de naturaleza, desarrollo, gobernanza

\section{ABSTRACT}

The tourism sector has played an important role in the economic development of Mexico. The federal government has made tourism a priority because of the power it has to improve local conditions and generate jobs. Unlike sun and beach tourism, the possibilities of alternative tourism have been highlighted as a way to improve local conditions through local empowerment. Nature tourism has not managed to be a fully successful strategy to address the problems of poverty and marginalization of the rural environment, especially in terms of creating jobs 
and generating income for communities. The objective of this research is to analyze the elements that make up and intervene in the development of this sector and identify the areas of opportunity. Prospective methods have been used to create possible futures with the tools Mic-Mac ${ }^{\circledast}$ and Smic Prob-Expert ${ }^{\circledast}$. The analysis of scenarios enabled us to identify future pictures with different probabilities of occurrence, among which a pessimistic, tendential and optimistic scenario was highlighted. The best optimistic scenario was selected and established as a baseline for the execution of the future of nature tourism on the Jalisco coast.

Keywords: Prospective analysis, nature tourism, development, governance

\section{INTRODUCCIÓN}

Frecuentemente se señala la necesidad del desarrollo de modelos turísticos más competitivos en el fluctuante mercado del turismo, que permitan mejorar los beneficios de desarrollo económico y social en el mundo. Entre los retos para lograrlo se apunta a la diversificación de productos y articulación un marco de Política de Estado, donde el turismo de naturaleza, entendido en general como los viajes que se realizan para disfrutar de ambientes naturales e incluye todas las formas de turismo relacionadas con el uso de recursos naturales como paisaje, agua, vegetación, topografía y vida silvestre entre otros (Kurt et al., 2016), se vislumbra como una alternativa potencial que se alinea con la demanda mundial creciente y a su vez con los Objetivos de Desarrollo Sostenible reconocidos por la Organización de Naciones Unidas.

Así, la Secretaría de Turismo en México (SECTUR, 2017) ha reconocido el valor del turismo de naturaleza, vinculando varios programas nacionales a la Estrategia para el Impulso y Desarrollo del Turismo de Naturaleza en México. La costa de Jalisco, con un largo y diferenciado historial de desarrollo turístico ha incursionado en el turismo de naturaleza, por lo que el objetivo de este trabajo es hacer un diagnóstico prospectivo y establecer escenarios probables que permitan la toma de decisiones.

\subsection{La planeación prospectiva}

La prospectiva es un proceso sistemático y participativo desarrollado con el objetivo de generar conocimiento, "desarrollar inteligencia", sobre el futuro de la ciencia y la tecnología mediante la construcción de visiones a medio y largo plazo que permitan tomar decisiones hoy. Para ello, analiza los desarrollos de la ciencia, la tecnología, la sociedad y la economía junto con las interacciones que existen para poder identificar cuáles son las acciones y estrategias que es preciso poner en marcha para poder generar el mayor beneficio social, la situación futura más favorable (Cabrera et al., 2007).

La prospectiva o ciencia del futuro, es una disciplina de carácter sistemático que estudia el futuro desde una perspectiva científica, con el objetivo de comprenderlo e influir en él. La OCDE siguiendo a Martin (2001:105), define la prospectiva como "el conjunto de tentativas sistemáticas para observar a largo plazo el futuro de la ciencia, la tecnología, la economía y la sociedad con el propósito de identificar los eventos o tendencias emergentes 
que probablemente produzcan los mayores beneficios económicos o sociales". Esta es una de las definiciones de mayor aceptación y la que habitualmente es citada en los textos de la especialidad.

Por su parte Medina y Ortegón (2006:127), definen la prospectiva como "un proceso de anticipación y exploración de la opinión experta proveniente de redes de personas e instituciones del gobierno, la empresa y las universidades, en forma estructurada, interactiva y participativa, coordinada y sinérgica, para construir visiones estratégicas de la ciencia y la tecnología y su papel en la competitividad y el desarrollo de un país, territorio, sector económico, empresa o institución pública".

En otras palabras, es una herramienta para informar la toma de decisiones, basada en pensar y debatir sobre el futuro incierto para definir cuáles son las áreas y factores que deben considerarse críticas para un determinado sector, en función de sus posibles impactos (Cabrera et al., 2007). El desarrollo del proceso permite identificar las oportunidades de actuación de que se dispone en la actualidad para conseguir los objetivos más favorables en función de la posición existente junto con los recursos y conocimientos necesarios.

\subsection{El turismo de naturaleza}

Existe un amplio espectro terminológico de acepciones del turismo alternativo que centran su atención en el uso de espacios de amplia fragilidad ambiental y sociocultural. En ocasiones dejan enfoques imprecisos y confusos. Es el caso del turismo de naturaleza, turismo de aventura, turismo rural, turismo comunitario, turismo en espacios naturales protegidos, ecoturismo, agroturismo y turismo sostenible. La OMT parte de la idea de que el turismo alternativo tiene como «motivación principal la observación y apreciación de la naturaleza y de las culturas tradicionales» (OMT, 2002:16). Tiene también como finalidad poner en contacto al turista con las distintas actividades y costumbres que se realizan en comunidades locales, donde se puede participar en las tareas rurales, en educación y conciencia ambiental, consumiendo productos de los diferentes territorios, o participando en tradiciones religiosas o culturales (Daltabuit et al., 2000).

Para Crosby (1994) es el turismo de visita a áreas naturales, que siempre implica el sostenimiento de la naturaleza (Lacambra, 1997); por ello el patrimonio natural, como imagen de destino se regula, para reducir impactos, y disfruta de gestión integrada a través de: Planes de Excelencia Turística, que han promovido la calidad y el efecto demostración; Planes Integrales de Calidad del Turismo, enfocados a nuevas ofertas, renovación de la existente, y aplicaciones a pequeña escala (ecotasas, certificados ambientales); y Planes Estratégicos, orientados a la gestión del destino turístico, y que han priorizado al entorno.

Presenta variantes que pueden incluir al ecoturismo, al turismo de aventura y el rural (Barrera y Muñoz, 2003), que pretenden, conservando el medio, desarrollar actividades como la observación de la naturaleza (fauna y ecosistemas), sideral (fenómenos espaciales, planetas, estrellas), de fósiles, visita a reservas naturales y parques, talleres de educación ambiental para conservación, proyectos de investigación biológica, y safari fotográfico, entre otras. Así pueden ser de turismo activo (terrestres, acuáticas o aéreas), y de esparcimiento pasivo. 
Conforma, pues, un modelo turístico relacionado con los condicionantes espaciales (localización, desplazamiento y distancia), paisajístico-perceptuales (valoración de escenarios no cotidianos) y ambientales, con el recurso ambiental en el concepto de paisaje, integrado por los procesos del medio físico y biótico, y que dispone de cualidades naturales, científicas y recreativas (Cebrián-Abellán et al., 2001). De ese modo, está construido sobre valores cualitativos, temáticos, de calidad, individualizados, de lo que deriva que los destinos deban de ajustarse a propuestas personales, cada vez más diversas e innovadoras.

La SECTUR (2004), intentando equilibrar la planificación y el desarrollo del turismo en territorios de elevada fragilidad con las exigencias, gustos y preferencias de quienes desean consumirlos, ha buscado unificar y estandarizar los criterios del turismo alternativo basándose en el punto de vista de quien compra y efectúa el viaje. De ahí surge el concepto de turismo de naturaleza, definido por este organismo como «los viajes que tienen como fin realizar actividades recreativas en contacto directo con la naturaleza y las expresiones culturales que la envuelven, con una actitud y compromiso de conocer, respetar, disfrutar y participar en la conservación de los recursos naturales y culturales».

El turismo de naturaleza, en cualquiera de sus variantes, constituye una importante fuente de empleo e ingresos económicos por su capacidad de desarrollo cuando se planifica y gestiona adecuadamente (Crosby, 1993; Cebrián-Abellán, 2008). La Comisión para la Cooperación Ambiental (CCA, 2000) apunta que entre el $40 \%$ y el $60 \%$ de los viajes turísticos internacionales son de personas que aprecian la naturaleza.

Wearing y Neil (2009) afirmaban, a finales del siglo pasado, que los viajes de naturaleza eran los de crecimiento más rápido, por encima de otras modalidades (se calculaba que crecían entre $10 \%$ y $30 \%$ al año a fines del siglo XX). No obstante, esta actividad no está exenta de posiciones encontradas (entre defensores y detractores).

El turismo de naturaleza integra al patrimonio natural con el turista. El primero incluye a la fauna y el hábitat, con sus características geológicas y paisajes, que permiten la práctica deportiva de naturaleza y el conocimiento en parques y zonas protegidas. Y el segundo se define por las motivaciones: bienestar físico, estímulo intelectual, disfrute de la naturaleza, contacto con escenarios personalizados e íntimos (Dirección General de Empresa, 2002).

A pesar de que existen numerosas definiciones del turismo de naturaleza, la mayoría coincide en que es un tipo de turismo con una fuerte dependencia de la naturaleza y preocupado por la conservación de los recursos naturales y culturales en el área donde se lleva a cabo. El turismo de naturaleza ha sido fuertemente promocionado en una gran variedad de áreas rurales del país, con el propósito de reforzar pequeñas y medianas organizaciones locales, así como por su responsabilidad social y ambiental. Uno de sus principales logros tiene que ver con los temas ambientales, sobre todo con su papel en la promoción del cambio de racionalidad entre los habitantes de las localidades respecto a la importancia de preservar los ecosistemas (Chávez-Dagostino, 2012).

Un estudio exploratorio reciente sobre el turismo de naturaleza en México (López Pardo y Palomino Villavicencio, 2015), determinó que gran parte de las empresas que nacen son indígenas con un ciclo de vida corto. Destacan también, que éstas se concentran en las regiones multiculturales de alta diversidad biológica y, que son organizaciones sociales que 
deben responder al mercado, a su comunidad, a los turistas y las iniciativas de sustentabilidad. Una gran parte de los proyectos comunitarios han sido apoyados por acciones gubernamentales de combate a la pobreza y para la conservación ambiental, donde la forma dominante es el ecoturismo.

En los últimos años algunas investigaciones dan cuenta de la utilidad y beneficios de la planeación prospectiva en el turismo de naturaleza, donde el establecimiento de escenarios futuros se propone como una herramienta indispensable en la integración de la ciencia con las partes interesadas (actores) a diferentes escalas, lo que permite explorar opciones alternativas de gestión y de recursos naturales en situaciones de alta incertidumbre (Bohensky et al., 2011; Macedo Ribeiro y Nascimento, 2014).

La exploración de áreas recreativas potenciales y la investigación de oportunidades de desarrollo de turismo de naturaleza utiliza frecuentemente diagnósticos con base al análisis de fortalezas, oportunidades, debilidades y amenazas (Khoshtaria y Chachava, 2017) como parte de la planeación prospectiva.

El impacto que genera y la complejidad general del turismo, elevan la necesidad de que sus vías futuras sean sustentables y tengan también sustento teórico. Un mecanismo popular que puede abordar esta necesidad es el análisis de escenarios, pero Moriarty (2012) considera que éste se basa en una praxis de amplia base en lugar de una teoría donde debe avanzarse en la investigación turística. El análisis de escenarios busca contribuir a la sostenibilidad al proponer entornos futuros hipotéticos que exponen las estructuras y dependencias de los estados de cosas actuales, probando así su capacidad de recuperación o adecuación continua bajo diferentes presiones evolutivas.

Una evaluación de los cambios en las percepciones al comienzo y al final de los ejercicios participativos para la construcción de escenarios, sugiere que los participantes se vuelvan más conscientes de los procesos sociales y del ecosistema que ocurren a grandes escalas espaciales y temporales (Bohensky et al., 2011).

En este sentido, tomando en cuenta la afirmación fundamental de la prospectiva es que "hay varios futuros posibles". Comprender su significado y alcance resulta indispensable para visualizar el eje central de esta disciplina que construye escenarios futuros de largo plazo de la sociedad, las regiones y las organizaciones (Ramírez, 2004). La Prospectiva parte del principio lógico e indispensable que el futuro aún no existe y "se puede concebir como un realizar múltiple" (Jouvenel, 1964) que "depende solamente de la acción del hombre" (Godet, 2000). Por esa razón, la persona puede construir el mejor futuro posible, tomando las decisiones correctas en el momento apropiado. Existen muchos futuros posibles, aunque en el momento unos pocos tienen las mayores probabilidades de ocurrencia.

En este sentido, analizar el estado actual para proyectar acciones hacia el futuro en la etapa de planificación de un territorio es hacer alusión a los aspectos sintomáticos que le dan representatividad a dichos entornos.

El desarrollo regional ha sido, desde hace tiempo, una de las principales políticas estructurales del país. Su objetivo es conseguir una distribución más equilibrada y sostenible de la riqueza, del bienestar y del desarrollo socioeconómico. A lo largo de los años, la importancia 
de la actividad política basada en las regiones ha crecido a medida que el gobierno nacional transfiere más poder a los niveles regionales.

De lo anterior se infiere entonces que, a partir de un diagnóstico, se sientan las bases para poder analizar y tratar de comprender un espacio específico y, por tanto, esta fase funciona como instrumento o herramienta que facilita tal aspecto, lo que posibilitó hacer el diagnóstico situacional de los contextos del turismo de naturaleza de la costa de Jalisco (TNCJ), así como el administrativo que impulsará los ejes estratégicos y los diversos proyectos específicos sustentados en los diferentes estados y escenarios circunscritos al turismo de naturaleza.

\subsection{La costa de Jalisco}

La colonización formal de la costa de Jalisco data de mediados del siglo XX donde hubo reparto de tierras (Tello Díaz, 2014) e iniciaría la dotación de caminos y otros equipamientos a lo largo de los aproximadamente $352 \mathrm{~km}$ de la costa y una superficie de $1.451 .466 \mathrm{ha}$ que comprende una franja de alta biodiversidad (Martínez y López-Pardo, 2010). Incluye cinco municipios: Puerto Vallarta, Cabo Corrientes, Tomatlán, La Huerta y Cihuatlán (véase la figura 1). En la década de los cincuenta, por política gubernamental se instalan un puerto en el sur de la costa jalisciense, Melaque y otro en el norte, Puerto Vallarta, con fines de transporte de productos agrícolas principalmente. Pronto la costa de Jalisco fue poblada, las tierras repartidas en ejidos y, extranjeros compraron parte de la costa que, luego se convertiría en el turismo de enclave, los ejidos hoy ofertan actividades de turismo alternativo, aprovechando las áreas naturales protegidas de la costa.

La actividad turística formal en la región fue posterior a otros destinos mexicanos como Cancún o Acapulco, debido al aislamiento en que la costa de Jalisco se encontraba en la década de los sesenta (Andrade-Romo, Chávez-Dagostino y Espinoza-Sánchez, 2010).

En el 2017 llegaron 39.3 millones de turistas internacionales a México (SECTUR, 2018b), Puerto Vallarta ocupa generalmente el 40 lugar como destino internacional en México (SECTUR, 2018a) y la costa de Jalisco en general contribuye con el $4.5 \%$ de los turistas internacionales en México.

Hoy confluyen dos marcas turísticas: Costalegre y Puerto Vallarta, que en conjunto reciben anualmente cerca de 5 millones de turistas donde Puerto Vallarta contribuye con cerca del 87\% (Secturjal, 2017).

La Costalegre es un corredor con una gran variedad de oferta (desde el turismo popular hasta el Gran Turismo) en distintas ubicaciones a lo largo de la costa. Existen unos desarrollos muy exclusivos de turismo de lujo en sitios selectos con una importante concentración en la costa en el municipio de La Huerta donde se concentra el denominado Gran Turismo (Riensche, 2016). El modelo dominante en Puerto Vallarta es el tradicional de sol y playa con una oferta diversa de servicios turísticos.

Así, el desarrollo de la costa está polarizado: en tanto el municipio localizado al norte de la región (Puerto Vallarta) se considera urbano, en el extremo sur, el municipio de Cihuatlán es de características predominantemente rurales, debido al tipo de actividades que realiza la 
población de la región (pesca, agricultura, ganadería y turismo), así como la escasez de servicios públicos e infraestructura con que cuenta (Chávez-Dagostino et al., 2006; Gobierno del Estado de Jalisco, 2013). En Puerto Vallarta, el nivel de marginación es muy bajo, mientras el municipio vecino de Cabo Corrientes estuvo enlistado hasta hace poco entre aquellos de nivel más alto de marginación en la entidad (Chávez-Dagostino et al., 2008). Hoy presenta un nivel medio igual que los municipios de Tomatlán y La Huerta. Otro indicador que evidencia un desarrollo diferenciado en la región es el crecimiento poblacional municipal, mientras Puerto Vallarta presentó una tasa anual promedio del 3.24\% entre los años 2005 y 2010 (COEPO, 2011), el resto de los municipios costeros presentó tasas menores al $3 \%$ o incluso negativas en años anteriores (Rodríguez, 2011).

Figura 1. Ubicación de los municipios costeros del estado de Jalisco, México

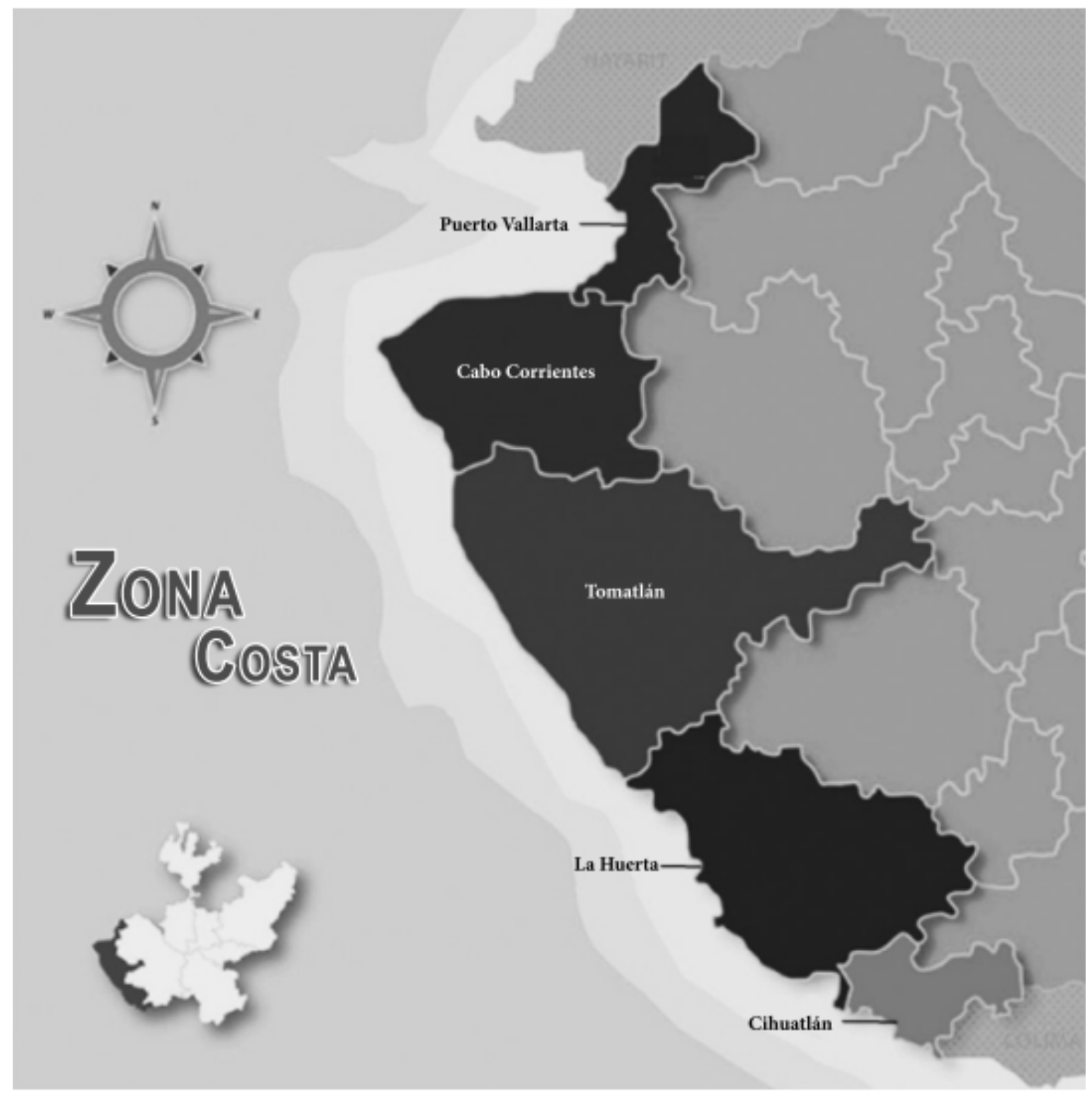

Fuente: Tomada de Mapa de la Zona Costera de Jalisco, por el Gobierno del Estado de Jalisco (2013) 
En esta región costera, se identificaron y caracterizaron 59 pequeñas y medianas empresas, tanto privadas como comunitarias dedicadas al turismo de naturaleza, algunas desarrolladas con apoyos del gobierno federal, en cuya variada oferta de actividades dominaron las tipificadas como de aventura, seguidas por las actividades de ecoturismo, mientras que el turismo rural está escasamente representado (Chávez-Dagostino et al., 2011).

\section{METODO}

El desarrollo metodológico global del Estudio de Prospectiva Regional consideró un conjunto de etapas consecutivas, las cuales formaron un todo que permitió alcanzar el objetivo general. La primera etapa consiste en la elaboración de una Línea Base Regional (diagnostico), con el fin de evaluar en qué medida la situación actual favorece o limita las potencialidades de desarrollo de futuro y, a la luz de esos antecedentes identificar las soluciones que incrementen las fortalezas o que sean capaces de minimizar o eliminar las debilidades y amenazas.

Cada componente y sector temático se construyó a partir de la revisión y sistematización del conocimiento y la experiencia disponibles, de los estudios realizados por los organismos públicos y entidades privadas de la costa de Jalisco, así como del análisis de nuevos antecedentes estadísticos disponibles por parte de los órganos de la administración pública y de los agentes privados. Se aplicó un procedimiento para definir la estructura del sistema regional y las relaciones entre las variables que se definieron en la Línea Base Regional.

El conjunto de variables fue determinado después de analizar en detalle los principales componentes del sistema, se identificaron las variables que caracterizan el sistema regional, fueron derivadas de nueve subsistemas: Conectividad, Gobernanza, Recursos Culturales, Recursos Naturales, Voluntad Pública, Recursos Mixtos, Publicidad y Promoción, Instituciones de Educación Superior y Prestadores de Servicios Turísticos.

Los especialistas o stakeholders, conformados por los directores de turismo de los cinco municipios, cinco prestadores de servicios turísticos de la Costa de Jalisco, tres representantes del sector académico, además de algunos empresarios y comerciantes en general de la región, analizaron en los diferentes componentes las variables determinando sus características, tendencias pasadas y proyecciones futuras, así como las posibles rupturas de las tendencias y los eventos que pueden modificar las evoluciones probables. Estos resultados fueron sometidos a la opinión de un amplio grupo de personas provenientes de diversos ámbitos (gubernamentales, científicos, empresariales y sociedad civil), en talleres de análisis y discusión.

En primer lugar, se definió un conjunto de 22 variables representativas de los componentes y sectores analizados en la Línea Base Regional, desprendidas de los nueve subsistemas identificados en el análisis de diagnóstico. Estas variables fueron sometidas a un proceso de homogenización por medio de una ficha estructurada para estos propósitos. Posteriormente las variables se sometieron a un análisis de impactos cruzados en una matriz de variables con el software MicMac ${ }^{\circledR}$. Para la identificación de variables claves la técnica es el MICMAC Matrices de Impactos cruzados Multiplicación Aplicada para una Clasificación La comparación de la jerarquización de las variables en las diferentes clasificaciones (directa, indirecta y potencial) es un proceso rico en enseñanzas. Ello permite confirmar la importancia de ciertas 
variables, pero de igual manera permite desvelar ciertas variables que en razón de sus acciones indirectas juegan un papel principal (y que la clasificación directa no ponía de manifiesto). Los resultados anteriormente anunciados en términos de influencia y de dependencia de cada variable pueden estar representados sobre un plano (el eje de abscisas corresponde a la dependencia y el eje de ordenadas a la influencia). Así, otro punto de referencia de las variables más influyentes del sistema estudiado, dan interés a las diferentes funciones de las variables en el sistema.

Cada cruce de variables fue evaluado, por un equipo de expertos, definiendo si existe una relación de influencia directa y luego se evalúa su grado (débil, moderada, fuerte). Los resultados permitieron clasificar las variables según su grado de dependencia/influencia, directa en un primer paso, e indirecta luego, por elevación a potencia de la matriz. Con esta información de influencia/dependencia, directa e indirecta, se procedió a agrupar las variables en campos, de acuerdo a su posición en el espacio de relaciones y teniendo presente sus características.

Estos agrupamientos pasaron a conformar macro variables, que fueron las utilizadas, luego, para la construcción de los escenarios. Luego se generó un juego de hipótesis respecto a las evoluciones probables y tendenciales de esas variables, las que fueron sometidas a una probabilización para definir las combinaciones de mayor probabilidad de ocurrencia con el software Smic Prob-Expert ${ }^{\circledR}$. Los métodos de impactos cruzados probabilistas vienen a determinar las probabilidades simples y condicionadas de hipótesis o eventos, así como las probabilidades de combinaciones de estos últimos, teniendo en cuenta las interacciones entre los eventos y/o hipótesis. El objetivo de estos métodos no es solamente el de hacer destacar los escenarios más probables, sino también el de examinar las combinaciones de hipótesis que serán excluidas a priori.

Con esas combinaciones más probables se confeccionaron los escenarios alternativos de futuro, los cuales son sometidos a consideración de la sociedad regional y de las autoridades encargadas de llevar a cabo los procesos de planificación, para finalmente optar por el escenario que resulte más deseable. La gestión del desarrollo regional tomará como base ese escenario, a partir del cual se deben definir las estrategias y las políticas que hagan factible su logro.

\section{ANALISIS FODA DEL TURISMO DE NATURALEZA EN LA COSTA DE JALISCO}

El análisis de la situación de un espacio territorial implica entender la dialéctica existente entre los diferentes actores, sectores y factores que cohabitan dicho espacio. La planificación estratégica territorial constituye, sin lugar a dudas, uno de los pasos fundamentales para construir los diferentes escenarios en los cuales se verán inmersos dichos sectores, actores y factores, ya aludidos; sin embargo, dicha construcción se cimentó en identificar las diferentes capacidades, competencias que le posibilitarán aprovechar las fortalezas y redoblar esfuerzos para subsanar las debilidades que le aquejan a dicho espacio, con el objeto de que se generen las sinergias necesarias que, a través del asociativismo de los diferentes recursos existentes, permitan el aprovechamiento de las oportunidades que se le presenten al 
territorio, así como identificar las debilidades inherentes para convertirlas, mediante acciones estratégicas en fortalezas.

Lo anterior implica entonces hacer uso de alguna herramienta estratégica que facilite dicho estudio, como lo es el análisis de: Fortalezas, Oportunidades, Debilidades y Amenazas (FODA), cuya aplicación es a través de la formulación de un objetivo que posibilita su operacionalización (Steiner, 1998). Para este estudio, se presenta el instrumento que, a posteriori, fungirá como generador de tácticas y acciones estratégicas encaminadas a la consecución de dicho objetivo para La Costa de Jalisco en materia del turismo de naturaleza.

A partir del ejercicio participativo: Costa de Jalisco en la construcción de su visión de desarrollo al 2030, se definieron los FODA presentes en la Costa de Jalisco, con los siguientes cinco factores internos y externos que lo definen:

\section{Fortalezas}

1. Gobernanza (Existe estabilidad en la gobernabilidad de municipios)

2. La riqueza de vida silvestre y paisaje son atractivos (belleza de especies y paisajes)

3. Recursos Naturales y Culturales (Riqueza de recursos)

4. Prestadores de servicios turísticos (Existencia de PST certificados y con experiencia)

5. Proyectos comunitarios (Existencia de proyectos comunitarios exitosos en turismo de naturaleza)

\section{Oportunidades}

1. Acceso a mercados cercanos (Cercanía con Puerto Vallarta y manzanillo)

2. Cultura y tradiciones (Región con riqueza cultural y tradiciones festivas)

3. Creciente interés por actividades de turismo de naturaleza (Aumento notorio en la demanda de esta actividad)

4. Ordenamiento de la actividad turística (La región cuenta con planes y normas de ordenamiento)

5. Regularización de la tierra (Programa de regularización del territorio)

\section{Debilidades}

1. Conectividad (Aeropuerto solo en Puerto Vallarta, la carretera se encuentra en ampliación y remodelación)

2. Tenencia de la tierra (Existe tenencia ejidal, comunal y pequeña propiedad)

3. Promoción y publicidad (Poca promoción y publicidad de este segmento turístico, incluso en Puerto Vallarta)

4. Infraestructura turística (Escasa infraestructura exceptuando Puerto Vallarta)

5. Inexistencia de política pública sobre turismo de naturaleza (No existe política pública definida) 


\section{Amenazas}

1. Fenómenos naturales (Región susceptible a huracanes)

2. Debilidad de cultura turística por parte de los pobladores (Población en transición de pesca al turismo exceptuando Puerto Vallarta)

3. Condiciones climáticas (Temporadas de lluvia prolongadas)

4. Infraestructura tecnológica (Nula infraestructura tecnológica fuera de Puerto Vallarta)

5. Migración de jóvenes a centros urbanos (Falta de fuerza laboral en 4 municipios)

Con estos factores se realizó una matriz en donde los actores, mediante consenso en un ejercicio participativo, asignaron intensidades de impactos internos y externos. Se otorgó un valor numérico de $0-3$ ( $0=$ sin impacto; $1=$ impacto débil; $2=$ impacto medio; $3=$ impacto fuerte) para establecer la intensidad del impacto. Los objetivos estratégicos se establecieron de acuerdo a los valores obtenidos de la sumatoria ( $\Sigma$ ) de FO, FA, DO y DA, el resultado de la columna final es la sumatoria de la intensidad de los impactos del renglón de la matriz, mientras que el resultado del último renglón de la matriz es la sumatoria de la intensidad de los impactos de su columna, los valores intermedios son el resultado de la sumatoria de las intensidades de impacto por cuadrante (tabla 1 ).

Tabla 1. Matriz de evaluación de la intensidad de impactos entre factores internos y externos

\begin{tabular}{|c|c|c|c|c|c|c|c|c|c|c|c|c|}
\hline & \multicolumn{5}{|c|}{ OPORTUNIDADES (O) } & \multicolumn{5}{|c|}{ AMENAZAS (A) } & \multirow{2}{*}{$\Sigma$} \\
\hline & & 1 & 2 & 3 & 4 & 5 & 1 & 2 & 3 & 4 & 5 & \\
\hline \multirow{5}{*}{ 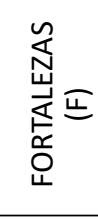 } & 1 & 3 & 2 & 2 & 3 & 3 & 1 & 2 & 1 & 2 & 2 & 21 \\
\hline & 2 & 3 & 2 & 3 & 1 & 1 & 1 & 1 & 1 & 1 & 2 & 16 \\
\hline & 3 & 3 & 3 & 3 & 1 & 1 & 1 & 1 & 1 & 1 & 1 & 16 \\
\hline & 4 & 3 & 3 & 3 & 2 & 2 & 1 & 2 & 1 & 2 & 2 & 21 \\
\hline & 5 & 3 & 3 & 3 & 2 & 3 & 1 & 2 & 1 & 2 & 3 & 23 \\
\hline & & 49 & & & & 61 & 37 & & & & 36 & \\
\hline \multirow{5}{*}{ 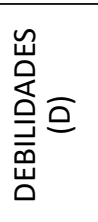 } & 1 & 3 & 3 & 2 & 2 & 1 & 1 & 1 & 1 & 1 & 1 & 16 \\
\hline & 2 & 1 & 1 & 1 & 2 & 3 & 1 & 1 & 1 & 2 & 2 & 15 \\
\hline & 3 & 3 & 2 & 2 & 1 & 1 & 1 & 2 & 1 & 2 & 2 & 17 \\
\hline & 4 & 3 & 2 & 3 & 2 & 1 & 1 & 2 & 1 & 2 & 2 & 19 \\
\hline & 5 & 3 & 2 & 2 & 2 & 1 & 1 & 3 & 1 & 2 & 2 & 19 \\
\hline & & 28 & 23 & 24 & 18 & 17 & 10 & 17 & 10 & 17 & 19 & \\
\hline
\end{tabular}

Fuente: Elaboración propia con base a Ponce (2007).

\subsection{Objetivos estratégicos derivados del FODA}

FO- Incentivar la colaboración entre el Ayuntamiento y la comunidad local para generar proyectos comunitarios, aprovechando el interés de las distintas dependencias de gobierno.

FA- Involucrar a diferentes instituciones públicas (SECTUR, Ayuntamientos, universidades, CONANP) y privadas (OSC, universidades, consultorías) en la capacitación de los Prestadores de Servicios Turísticos para el manejo de visitantes a la región aprovechando el posicionamiento que tiene la región como destino de "Naturaleza".

DO- Aprovechar la cercanía a destinos consolidados como Puerto Vallarta y Manzanillo para mejorar la publicidad y promoción de toda la región. 
DA- Incrementar la infraestructura turística para detener la migración de los jóvenes y aprovechar los recursos naturales para actividades turísticas.

Estrategias FO: Aplican a las fuerzas internas para aprovechar la ventaja de las oportunidades externas.

Estrategias FA: Aprovechan las fuerzas internas para evitar o disminuir las repercusiones de las amenazas externas.

Estrategias DO: Pretenden superar las debilidades internas aprovechando las oportunidades externas.

Estrategia DA: Son tácticas defensivas que pretenden disminuir las debilidades internas y evitar las amenazas del entorno.

\subsection{Conclusiones del FODA}

- Las principales oportunidades son que existe un creciente interés por las actividades de turismo de naturaleza (24), además de que existen mercados cercanos (28) y la oportunidad general es el ordenamiento territorial y turístico.

- Las fortalezas de mayor impacto son, los proyectos comunitarios que hay en la actualidad y que se proyecta existan en el futuro (23), además la existencia de prestadores de servicios turísticos con gran capacidad (21) y la gobernanza que existe en la región (21).

- Las principales debilidades son la falta de infraestructura turística (19) y la inexistencia de política pública sobre el turismo de naturaleza (19).

- La principal amenaza es la migración de jóvenes a centros urbanos (19).

- Sobresale la relación FO por su impacto (61), por lo que se recomienda una estrategia "ofensiva" para aprovechar las oportunidades externas empleando las fortalezas, y no descuidar las debilidades de mayor impacto minimizando las amenazas.

- Es indispensable el ordenamiento de la actividad turística para la conservación del ecosistema y la satisfacción de los visitantes.

\section{ANALISIS PROSPECTIVO DEL TURISMO DE NATURALEZA EN LA COSTA DE JALISCO}

Con el fin de elaborar un marco de referencia para la construcción de los escenarios futuros, se desarrolló un estudio de análisis estructural como herramienta para propiciar la reflexión colectiva (IPAE, 2009) que permitiera identificar las variables clave que representan el TNCJ. El análisis estructural implica la identificación de las variables que describen el sistema, el análisis de relaciones entre variables y la identificación de las variables estratégicas, se determinó que existían veintidós (22) variables representativas para el TNCJ, caracterizadas por ser entendibles y mutuamente excluyentes. Las variables se asociaron de acuerdo con sus características a las dimensiones conectividad, Gobernanza, Recursos culturales, Recursos naturales, Voluntad pública. Recursos Mixtos, Publicidad y promoción, Instituciones de educación superior y Prestadores de servicios turísticos que representan el territorio de la costa de Jalisco. De esta manera fue posible establecer una base fuerte para la reflexión prospectiva. 
En la tabla 2, se enumeran las variables que describen al Turismo de naturaleza de la Costa de Jalisco, agrupadas por dimensión.

Tabla 2: Variables del Turismo de Naturaleza en la Costa de Jalisco

\begin{tabular}{|c|c|c|c|c|}
\hline $\mathbf{N}^{\circ}$ & ETIQUETA & $\begin{array}{l}\text { ETIQUETA } \\
\text { CORTA }\end{array}$ & DESCRIPCION & TEMA \\
\hline 1 & $\begin{array}{l}\text { Cercanía con un destino } \\
\text { importante }\end{array}$ & V1 & $\begin{array}{l}\text { Aprovechamiento de un destino } \\
\text { consolidado como Puerto Vallarta. }\end{array}$ & Conectividad \\
\hline 2 & Ayuntamiento & V2 & Apoyo por parte del Ayuntamiento & Gobernanza \\
\hline 3 & Patrimonio Cultural & V3 & $\begin{array}{l}\text { Aprovechamiento de los recursos } \\
\text { culturales existentes en la región. }\end{array}$ & Recursos Culturales \\
\hline 4 & $\begin{array}{l}\text { Regularización de tierras de } \\
\text { comunidades Indígenas }\end{array}$ & V4 & Aseguramiento de Títulos de propiedad. & Gobernanza \\
\hline 5 & $\begin{array}{l}\text { Biodiversidad y recursos } \\
\text { naturales }\end{array}$ & V5 & $\begin{array}{l}\text { Aprovechamiento de la biodiversidad } \\
\text { existente en la región. }\end{array}$ & Recursos Naturales \\
\hline 6 & Accesibilidad por mar y tierra & V6 & $\begin{array}{l}\text { Aprovechamiento de las rutas terrestres } \\
\text { y marítimas. }\end{array}$ & Conectividad \\
\hline 7 & $\begin{array}{l}\text { Apertura de las oportunidades } \\
\text { como destino turístico }\end{array}$ & V7 & $\begin{array}{l}\text { Fomento de una cultura turística en la } \\
\text { población. }\end{array}$ & Voluntad pública \\
\hline 8 & Comunidad Indígena & V8 & $\begin{array}{l}\text { Aprovechamiento de las riquezas } \\
\text { culturales y del territorio. }\end{array}$ & Recursos mixtos \\
\hline 9 & Plan turístico local & V9 & $\begin{array}{l}\text { Estructuración de un desarrollo turístico } \\
\text { local. }\end{array}$ & Gobernanza \\
\hline 10 & Conectividad & V10 & $\begin{array}{l}\text { Aprovechamiento de las rutas terrestres } \\
\text { y marítimas. }\end{array}$ & Conectividad \\
\hline 11 & Áreas naturales protegidas & V11 & $\begin{array}{l}\text { Aprovechamiento de recursos } \\
\text { Naturales. }\end{array}$ & Recursos Naturales \\
\hline 12 & Paisaje & V12 & $\begin{array}{l}\text { Aprovechamiento de los recursos } \\
\text { naturales y culturales de la región. }\end{array}$ & Recursos mixtos \\
\hline 13 & Fauna & V13 & $\begin{array}{l}\text { Aprovechamiento de la fauna existente } \\
\text { en la región }\end{array}$ & Recursos Naturales \\
\hline 14 & Planes de ordenamiento & V14 & $\begin{array}{l}\text { Uso racional y armónico del espacio } \\
\text { territorial y sus recursos. }\end{array}$ & Gobernanza \\
\hline 15 & Publicidad & V15 & $\begin{array}{l}\text { Promover y difundir los atractivos y } \\
\text { servicios turísticos de la región. }\end{array}$ & $\begin{array}{l}\text { Publicidad y } \\
\text { Promoción }\end{array}$ \\
\hline 16 & $\begin{array}{l}\text { Unidades de Manejo para } \\
\text { la Conservación de la Vida } \\
\text { Silvestre }\end{array}$ & V16 & $\begin{array}{l}\text { Aprovechamiento de la flora y de la } \\
\text { fauna de la región. }\end{array}$ & Recursos Naturales \\
\hline 17 & Proyectos ejidales & V17 & Integración de la comunidad ejidal. & Gobernanza \\
\hline 18 & Voluntad de Actores & V18 & $\begin{array}{l}\text { Integración de la comunidad en el } \\
\text { desarrollo de proyectos. }\end{array}$ & Voluntad pública \\
\hline 19 & Recurso hídrico & V19 & $\begin{array}{l}\text { Aprovechamiento de los recursos } \\
\text { hídricos de la región. }\end{array}$ & Recursos Naturales \\
\hline 20 & Académico & V20 & Apoyo de las estancias académicas & $\begin{array}{l}\text { Instituciones de } \\
\text { educación superior }\end{array}$ \\
\hline 21 & Prestadores de servicios & V21 & $\begin{array}{l}\text { Utilizar el conocimiento y los servicios } \\
\text { de los prestadores de servicios turísticos } \\
\text { de la región. }\end{array}$ & PST \\
\hline 22 & Conservación de recursos & V22 & $\begin{array}{l}\text { Conservación de los recursos existentes } \\
\text { en la región. }\end{array}$ & Recursos mixtos \\
\hline
\end{tabular}

Fuente: Elaboración Propia, con ayuda del software MicMac ${ }^{\circledR}$. 
Para analizar las relaciones entre las variables se utilizó el software $\mathrm{MicMac}^{\circledR}$ (Matriz de impacto cruzado multiplicación aplicada para una clasificación) La matriz de análisis estructural que se introdujo en el software se obtuvo a través del proceso de unificación de las distintas matrices diligenciadas por cada uno de los expertos que participaron en la etapa de análisis estructural. Comparar las relaciones directas, indirectas y potenciales, cobra importancia en la medida en que pueden ser asociadas en un horizonte temporal aproximado.

Ahora bien, el análisis de las relaciones directas se realiza mediante la matriz de influencias directas (MID), cuya valoración fue realizada por expertos del Sistema, al igual que la matriz de influencias directas potenciales (MIDP). Por otra parte, la matriz de influencias indirectas (MII) y la matriz de influencia indirectas potenciales (MIIP), fueron obtenidas mediante el software $\mathrm{MicMac}^{\circledR}$, las cuales fueron necesarias para los análisis de las respectivas relaciones.

Las relaciones entre variables implican el análisis de las condiciones de influencia y dependencia existentes entre ellas. La influencia es el grado de poder que ejerce una variable sobre las restantes que representan el sistema, y la dependencia es el grado en el cual una variable se ve afectada por las otras variables que representan el sistema.

De esta manera, a partir de la matriz de influencia directa, se elaboró un análisis del comportamiento de las variables según las condiciones de influencia y dependencia a corto plazo, permitiendo identificar las variables sobresalientes en ambos casos.

En la figura 2 es posible observar el comportamiento de las variables según el índice de influencia: del corto a mediano plazo de las variables sufren un cambio de posición; sin embargo, el sistema no sufre una variación significativa en el comportamiento, debido a que este cambio no es brusco. Ahora, al analizar los cambios del mediano al largo plazo, se puede observar que pocas variables cambian sus condiciones de influencia. Es importante resaltar que varias variables disminuyeron significativamente su influencia del mediano al largo plazo.

Figura 2. Clasificación de las variables según sus influencias y su dependencia

Classify variables according to their influences

\begin{tabular}{|c|c|c|c|c|c|c|c|}
\hline Rank & Variable & \begin{tabular}{|l} 
Variable \\
\end{tabular} & Variable & Rank & Variable & \begin{tabular}{|l} 
Variable \\
\end{tabular} & Variable \\
\hline 1 & $14 \cdot V 14$ & $14 \cdot \sqrt[V 14]{ }$ & $14 \cdot V 14$ & 1 & $14 \cdot \sqrt{14}$ & $17 \cdot \sqrt{17}$ & $14 \cdot V 14$ \\
\hline 2 & $21 \cdot \sqrt{2} 21$ & $21 \cdot \sqrt{2} 21$ & $21 \cdot \sqrt{ } 21$ & 2 & $17 \cdot \mathrm{V} 17$ & $14 \cdot V / 14$ & $17 \cdot \sqrt[V]{ } 17$ \\
\hline 3 & 9.V9 & $9 \cdot 1 / 9$ & 9.V9 & 3 & $18 \cdot V 18$ & $18 \cdot V 18$ & $18 \cdot V 18$ \\
\hline 4 & $12 \cdot \mathrm{V} 12$ & $12 \cdot \mathrm{V} 12$ & $12 \cdot \mathrm{V} 12$ & 4 & $21 \cdot V 21$ & $21 \cdot \sqrt[V]{21}$ & $21 \cdot \sqrt{2} 21$ \\
\hline 5 & $4 \cdot \sqrt{ } / 4$ & $4 \cdot V / 4$ & $4 \cdot \sqrt{4}$ & 5 & 9.V9 & $9 \cdot \sqrt{9}$ & $9 \cdot \sqrt{9}$ \\
\hline 6 & $8 \cdot \mathrm{V} 8$ & $8 \cdot V^{2}$ & $8 \cdot V 8$ & 6 & $20 \cdot \sqrt{2} 20$ & $20 \cdot \sqrt{20}$ & $20 \cdot \sqrt{20}$ \\
\hline 7 & $11 \cdot V 11$ & $11 \cdot V 11$ & $11 \cdot V 11$ & 7 & $22 \cdot \sqrt{22}$ & $22 \cdot \sqrt{22}$ & $22 \cdot \sqrt[V]{22}$ \\
\hline 8 & $6 \cdot 16$ & $13 \cdot \mathrm{V} 13$ & $6 \cdot V_{6}$ & 8 & $8 \cdot \mathrm{V} 8$ & $8 \cdot \mathrm{V} 8$ & $8 \cdot V 8$ \\
\hline 9 & $13 \cdot \mathrm{V} 13$ & $6 \cdot 16$ & $13 \cdot \mathrm{V} 13$ & 9 & $7 \cdot \sqrt{ } 7$ & $7 \cdot \sqrt{ } 7$ & $7 \cdot V / 7$ \\
\hline 10 & $7 \cdot V 7$ & $22 \cdot \sqrt{22}$ & $7 \cdot \sqrt{ } 7$ & 10 & $5 \cdot \mathrm{V} 5$ & $16 \cdot \sqrt[V]{ } 16$ & $5 \cdot V 5$ \\
\hline 11 & $22 \cdot \sqrt{ } 22$ & $7 \cdot V 7$ & $22 \cdot \sqrt[V]{22}$ & 11 & $10 \cdot \mathrm{V} 10$ & $5 \cdot \vee 5$ & $10 \cdot \mathrm{V} 10$ \\
\hline 12 & $5 \cdot \mathrm{V} 5$ & $10 \cdot \mathrm{V} 10$ & $5 \cdot \mathrm{V} 5$ & 12 & $12 \cdot V 12$ & $15 \cdot V 15$ & $12 \cdot \mathrm{V} 12$ \\
\hline 13 & $10 \cdot V 10$ & $18 \cdot V 18$ & $10 \cdot V 10$ & 13 & $13 \cdot V 13$ & $13 \cdot \sqrt[V]{ } 13$ & $13 \cdot V / 13$ \\
\hline 14 & $18 \cdot V 18$ & $5 \cdot \sqrt{ } 5$ & $18 \cdot V 18$ & 14 & $15 \cdot \mathrm{V} 15$ & $12 \cdot V 12$ & $15 \cdot V 15$ \\
\hline 15 & $2 \cdot \sqrt{2}$ & $2 \cdot \sqrt{2}$ & $2 \cdot \sqrt{2}$ & 15 & $16 \cdot V 16$ & $4 \cdot \sqrt{4}$ & $16 \cdot V 16$ \\
\hline 16 & $1 \cdot \mathrm{V} 1$ & $1 \cdot \mathrm{V} 1$ & $1 \cdot \mathrm{V} 1$ & 16 & $4 \cdot \sqrt{4}$ & $10 \cdot \mathrm{V} 10$ & $4 \cdot \sqrt{4}$ \\
\hline 17 & $16 \cdot V 16$ & $16 \cdot V 16$ & $16 \cdot V 16$ & 17 & $11 \cdot V 11$ & $11 \cdot V_{11}$ & $11 \cdot V 11$ \\
\hline 18 & $15 \cdot \mathrm{V} 15$ & $15 \cdot V 15$ & $15 \cdot \mathrm{V} 15$ & 18 & $3 \cdot \sqrt{3}$ & $3 \cdot \sqrt{3}$ & $3 \cdot 1 / 3$ \\
\hline 19 & $3 \cdot 1 / 3$ & $3 \cdot \sqrt{3}$ & $3 \cdot 1 / 3$ & 19 & $6 \cdot 16$ & $19 \cdot V 19$ & $6 \cdot 16$ \\
\hline 20 & $19 \cdot \mathrm{V} 19$ & $19 \cdot \mathrm{V} 19$ & $19 \cdot \mathrm{V} 19$ & 20 & $19 \cdot \mathrm{V} 19$ & $6 \cdot V_{6}$ & $19 \cdot \mathrm{V} 19$ \\
\hline 21 & $20 \cdot \sqrt{2} 20$ & $20 \cdot \mathrm{V} 20$ & $20 \cdot / 20$ & 21 & $2 \cdot \sqrt{2}$ & $2 \cdot \mathrm{V} / 2$ & $2 \cdot \sqrt{2}$ \\
\hline 22 & $17 \cdot \mathrm{V} 17$ & $17 \cdot V 17$ & $17 \cdot \mathrm{V} 17$ & 22 & $1 \cdot \mathrm{V} 1$ & $1 \cdot \mathrm{V} 1$ & $1 \cdot \mathrm{V} 1$ \\
\hline
\end{tabular}

Fuente: Elaboración Propia, con ayuda del software MicMac ${ }^{\circledR}$. 
En la figura 2 se puede observar el comportamiento de las variables según el índice de dependencia. Del corto al mediano plazo, $45 \%$ sufre un cambio de posición ( $23 \%$ aumenta la dependencia y $23 \%$ la disminuye). Vale resaltar que dicho movimiento se registra hacia posiciones cercanas, lo que implica que el sistema no sufre una variación significativa en el comportamiento. En relación con los cambios del mediano al largo plazo.

\subsection{Identificación de las variables estratégicas}

En esta etapa se identificaron aquellas variables estratégicas, las cuales presentan la mayor influencia y dependencia en el sistema, permitiendo que cualquier acción sobre las mismas genere un efecto en las variables que describen la totalidad del sistema.

Variables estratégicas. Para identificar estas variables se proyectaron cada una de las variables de conflicto en el plano de influencias indirectas potenciales, sobre una bisectriz ubicada desde la esquina superior derecha hasta la esquina inferior izquierda. En la figura 3 se observa la proyección de las variables de conflicto que permite establecer la priorización de las variables estratégicas.

Figura 3. Identificación de variables estratégicas

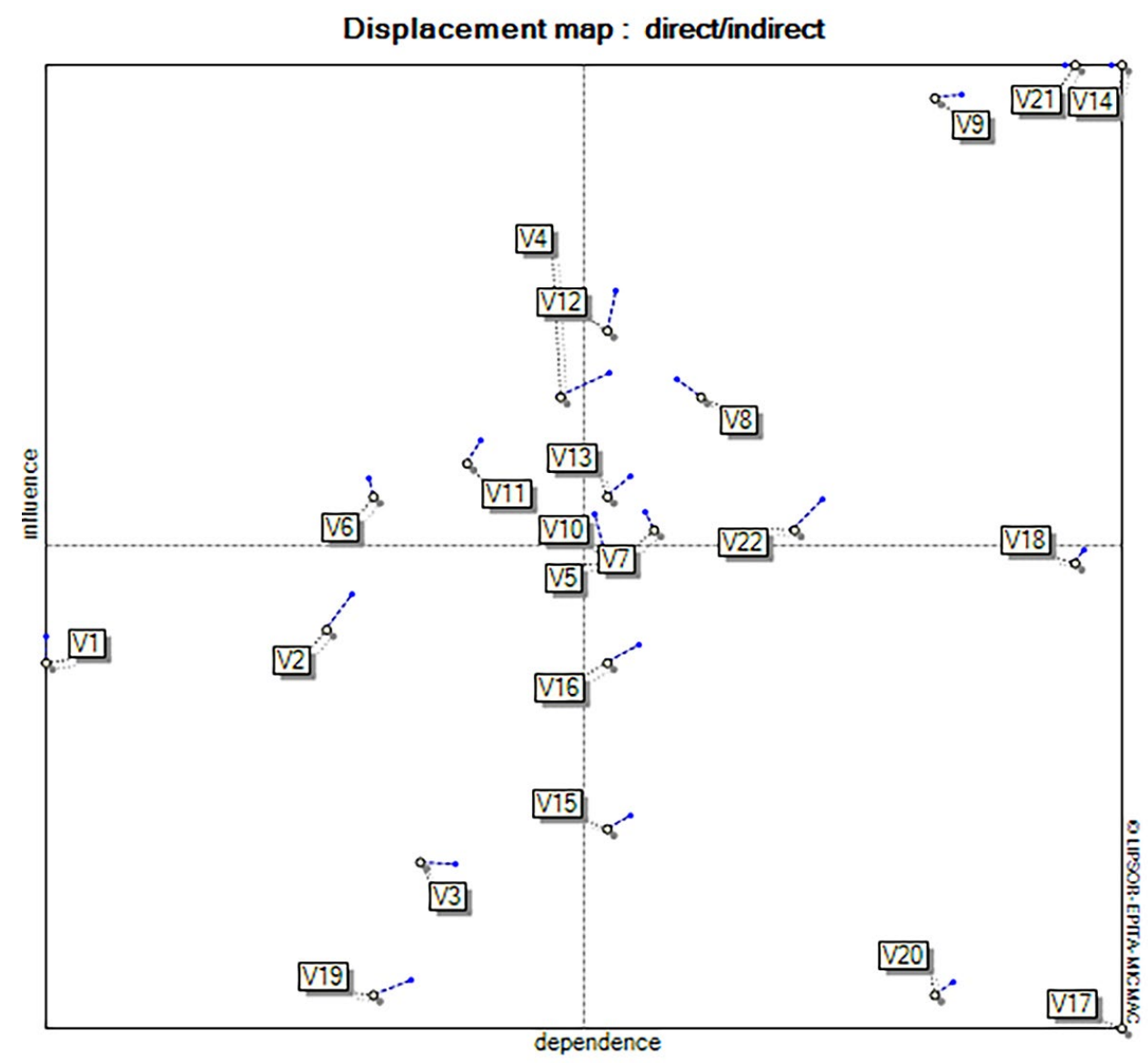

Fuente: Elaboración Propia, con ayuda del software MicMac ${ }^{\circledR}$. 
Con base en esta premisa, se identifican seis variables estratégicas, listadas a continuación:

1. Planes de Ordenamiento.

2. Prestadores de Servicios.

3. Plan Turístico Local.

4. Comunidad Indígena.

5. Apertura de las oportunidades como destino turístico.

6. Conservación de Recursos.

Figura 4. Influencias indirectas potenciales

Potential indirect influence graph

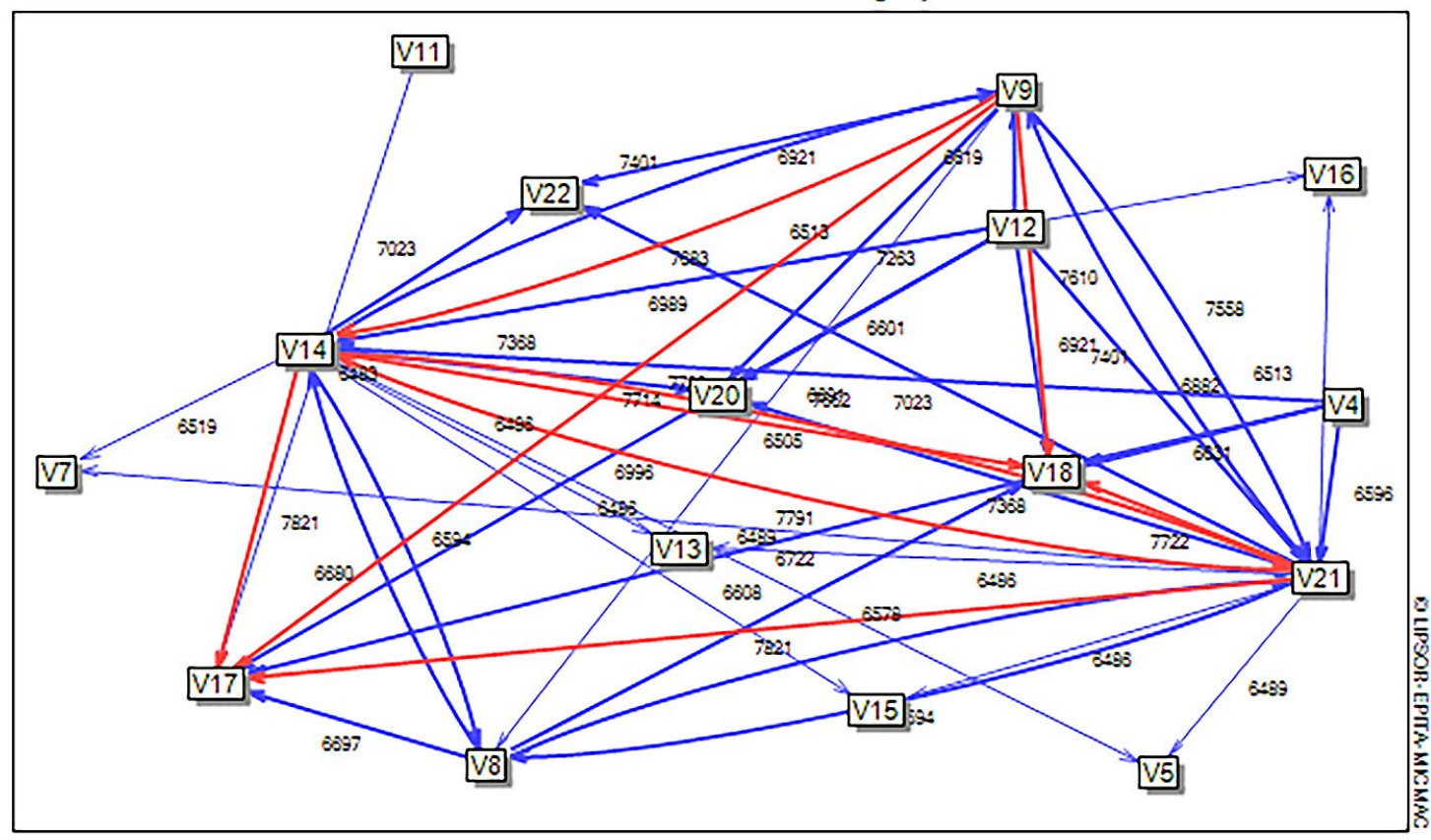

Weakest influences
- Weak influences
- Moderate influences
Relatively strong influences
- Strongest influences

Fuente: Elaboración Propia, con ayuda del software MicMac ${ }^{\circledR}$.

Por último, como se observa en la figura 4, las variables identificadas como estratégicas son aquellas que tienen tanto relaciones de "influencias relativamente importantes" como relaciones de "influencia más importantes", lo cual permite modificar el comportamiento del sistema y hacer que cualquier variación en una de ellas afecte las restantes.

Para el 2030 el TNCJ será de gran determinación e influencia relacionada con variables como: Planes de Ordenamiento, Prestadores de Servicios, Plan Turístico Local, Comunidad Indígena, Apertura de las oportunidades como destino turístico y Conservación de Recursos. Estas variables se consideran estratégicas y son base para la formulación de la visión del Turismo de Naturaleza en la Costa de Jalisco antes mencionada. 
Para el corto plazo, el TNCJ se verá determinado por Planes de Ordenamiento, Prestadores de Servicios, Plan Turístico Local, Paisaje, Regularización de tierras de comunidades Indígenas y Comunidad Indígena. Las variables más dependientes serán Planes de Ordenamiento, Proyectos Ejidales, Voluntad de Actores, Prestadores de Servicios, Plan turístico Local y Académico.

Para el mediano plazo, las variables que han influenciado en el corto plazo el TNCJ se mantienen, las cuales son Planes de Ordenamiento, Prestadores de Servicios, Plan Turístico Local, Paisaje, Regularización de tierras de comunidades Indígenas y Comunidad Indígena. Por otra parte, las variables más dependientes serán Proyectos Ejidales, Planes de Ordenamiento, Voluntad de Actores, Prestadores de Servicios, Plan turístico Local y Académico.

Para el largo plazo las variables que presentarán una alta influencia para el desarrollo del TNCJ serán Planes de Ordenamiento, Prestadores de Servicios, Plan Turístico Local, Paisaje, Regularización de tierras de comunidades Indígenas y Comunidad Indígena. Por otra parte, las variables más dependientes en el largo plazo serán Planes de Ordenamiento, Proyectos Ejidales, Voluntad de Actores, Prestadores de Servicios, Plan Turístico Local y Académico.

\subsection{Identificación de hipótesis}

A lo largo del proceso prospectivo se puede verificar la existencia de un hilo conductor que se origina en las variables consideradas como estratégicas, las cuales se convierten en eventos con los cuales se obtiene el escenario apuesta (Mojica, 2005). Con base en el análisis estructural y la participación de los actores se identificarán las hipótesis asociadas a las variables estratégicas.

De esta manera, se obtendrán las hipótesis de futuro asociadas a las variables estratégicas, a las cuales se les asigna un valor de probabilidad simple y compuesta, considerando la ocurrencia y la no ocurrencia de las mismas, generando un conjunto de escenarios que representan las imágenes de futuro para el Turismo de Naturaleza al año 2030. Se identificaron hipótesis para así, seleccionar las más probables de acuerdo con el software Smic Prob-Expert ${ }^{\circledR}$ (Tabla 3).

Tabla 3. Hipótesis de matrices de impactos cruzados (SMIC)

\begin{tabular}{|c|l|c|l|}
\hline $\mathbf{N}^{\circ}$ & \multicolumn{1}{|c|}{ Título largo } & $\begin{array}{c}\text { Título } \\
\text { corto }\end{array}$ & \multicolumn{1}{|c|}{ Descripción } \\
\hline 1 & Planes de Ordenamiento & H1 & Uso racional y armónico del espacio territorial y sus recursos. \\
\hline 2 & Prestadores de Servicios & H2 & $\begin{array}{l}\text { Utilizar el conocimiento y los servicios de los Prestadores de } \\
\text { Servicios turísticos de la región. }\end{array}$ \\
\hline 3 & Plan Turístico Local & H3 & Estructuración de un desarrollo turístico local. \\
\hline 4 & Comunidad Indígena & H4 & Aprovechamiento de las riquezas culturales y del territorio. \\
\hline 5 & $\begin{array}{l}\text { Apertura de las oportunidades } \\
\text { como destino turístico }\end{array}$ & H5 & Fomento de una cultura turística en la población. \\
\hline 6 & Conservación de Recursos & H6 & Conservación de los recursos existentes en la región. \\
\hline
\end{tabular}

Fuente: Elaboración propia con el software Smic Prob-Expert ${ }^{\circledR}$ 
La Probabilización de las hipótesis se realizó a través de una encuesta diligenciada a los stakeholders, conformados por los directores de turismo de los cinco municipios, cinco prestadores de servicios turísticos de la Costa de Jalisco, tres representantes del sector académico, además de algunos empresarios y comerciantes en general de la región, las cuales ya contestadas se les dio a cada hipótesis una probabilidad simple y condicionada de ocurrencia. En primer lugar, se califica el nivel de probabilidad de ocurrencia de cada hipótesis con una escala que va desde muy improbable hasta muy probable, pasando por los estados de improbable, tanto probable como improbable y probable de suceder, las cuales venían acompañadas de una escala numérica de 0.1 a 1, respectivamente a la probabilidad simple asignada; en la última columna, la probabilidad simple de ocurrencia corregida mediante la utilización del software Smic Prob-Expert ${ }^{\circledast}$. De esta manera, se puede concluir que la valoración asignada es optimista frente a la posible realización de las hipótesis; sin embargo, este análisis no permite observar la interrelación entre las mismas. Definidas las probabilidades simples, en la segunda parte se evalúa las probabilidades condicionadas entre los eventos. En primer lugar, se establecieron las probabilidades condicionadas positivas, y posteriormente se analizaron las probabilidades condicionadas negativas.

\subsection{Probabilización de Escenarios:}

La aplicación de esta técnica permitió evaluar las probabilidades de ocurrencia del conjunto de eventos teniendo en cuenta las interacciones existentes entre los mismos, con lo cual se identificaron las imágenes de futuro que, para este caso con seis hipótesis, corresponde a 64.

$$
\begin{aligned}
& 2^{n}=\text { Número de imágenes de futuro, } n=\text { Número de hipótesis } \\
& \qquad 2^{6}=64 \text { imágenes de futuro }
\end{aligned}
$$

La metodología permite agrupar las imágenes o escenarios de futuro en tres grupos: Escenarios alternos o núcleo tendencial, menos probables y los imposibles, de acuerdo con las probabilidades correspondientes a cada uno de los mismos, los cuales se describen a continuación. Escenarios alternos o núcleo tendencial Estos escenarios corresponden a aquellos que presentan la mayor probabilidad de ocurrencia de todos los escenarios posibles, por lo que seguramente el TNCJ para el año 2030 se encontrará en alguna de las imágenes de futuro que ellos describen (figura 5).

El escenario con menor probabilidad de ocurrencia es el 55 y 56 (0.001\%) justo en el límite permisible. Estos escenarios corresponden a aquellos que presentan la menor probabilidad de ocurrencia de todos los escenarios posibles, por lo que con seguridad el TNCJ para el año 2030 difícilmente se encontrará en alguna de las imágenes de futuro que ellos describen. Lo cual hace que no se incluyan en los escenarios del núcleo tendencial. Como el caso del escenario 4 (1111000), el cual tiene la probabilidad de ocurrencia cero. 
Figura 5. Probabilización de escenarios

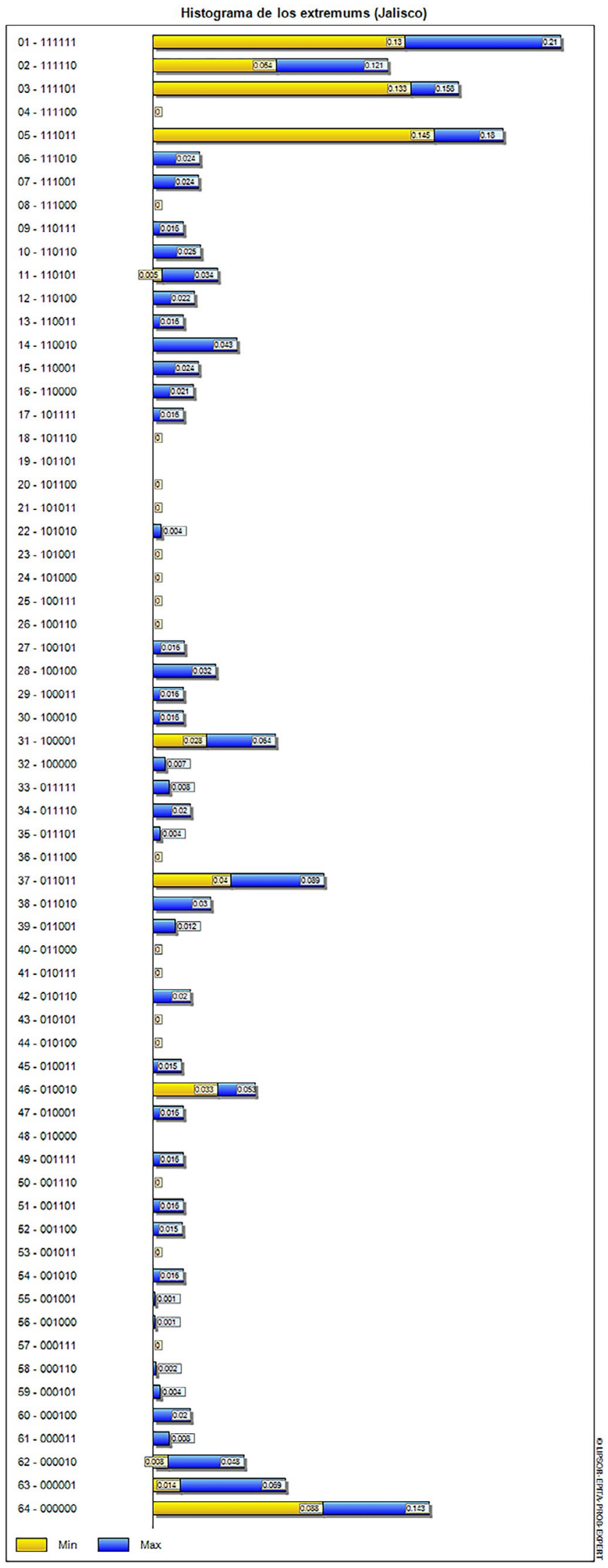


Escenarios imposibles Estos escenarios corresponden a aquellos que no presentan probabilidad de ocurrencia, por lo que el TNCJ para 2030 no se encontrará en alguna de las imágenes de futuro que ellos describen. En la figura 5 se presentan 19 escenarios 4, 8, 18, 19, $20,21,23,24,25,26,36,40,41,43,44,48,50,53$ y 57 de acuerdo con la probabilidad simple de ocurrencia, que se encuentran en una probabilidad de $0 \%$.

El escenario tendencial con una probabilidad de ocurrencia de $0.8 \%$ explica la ocurrencia al 2030 de las hipótesis (eventos) asociados a los Prestadores de Servicios, Plan Turístico Local, Comunidad Indígena, Apertura de las oportunidades como destino turístico y Conservación de Recursos; y la NO ocurrencia de las hipótesis (eventos) asociados a Planes de Ordenamiento (tabla 4). El escenario pesimista lo describe la NO ocurrencia de las seis hipótesis, con una probabilidad de que ocurra este escenario de 14.3\% (tabla 5). El escenario optimista con una probabilidad de ocurrencia de $21.0 \%$, explica que las hipótesis asociadas Planes de Ordenamiento, Prestadores de Servicios, Plan Turístico Local, Comunidad Indígena, Apertura de las oportunidades como destino turístico y Conservación de Recursos al 2030 se desarrollarán (tabla 6).

Tabla 4. Probabilidad del escenario tendencial

\begin{tabular}{|c|c|}
\hline Escenario & Probabilidad de que suceda \\
\hline $33-011111$ & 0.008 \\
\hline
\end{tabular}

Fuente: Elaboración propia con ayuda del software Smic Prob-Expert ${ }^{\circledast}$

Tabla 5. Probabilidad del escenario pesimista

\begin{tabular}{|c|c|}
\hline Escenario & Probabilidad de que suceda \\
\hline $64-000000$ & 0.143 \\
\hline
\end{tabular}

Fuente: Elaboración propia con ayuda del software Smic Prob-Expert ${ }^{\circledR}$

Tabla 6. Probabilidad del escenario optimista-apuesta

\begin{tabular}{|c|c|}
\hline Escenario & Probabilidad de que suceda \\
\hline $01-111111$ & 0.21 \\
\hline
\end{tabular}

\section{CONCLUSIONES}

El impulso y sustentabilidad de proyectos de turismo de naturaleza en los municipios de la costa de Jalisco deben originarse en una necesidad sentida de las propias comunidades. Dichos proyectos deben constituirse en alternativas reales para la generación de oportunidades de empleo, ingresos y mejora de la calidad de vida para sus pobladores. Al conjunto de actores les corresponde crear las condiciones económicas, institucionales, normativas y de generación de infraestructura que contribuyan a alcanzar este propósito sin poner en riesgo el medio ambiente y los recursos naturales del a región. 
La costa de Jalisco cuenta con una gran cantidad de atractivos naturales que pueden ser aprovechados turísticamente. Con una gestión responsable, el turismo de naturaleza puede contribuir a dar a conocer su riqueza y a la vez generar ingresos para las comunidades locales quienes podrían beneficiarse de los recursos tanto directa como indirectamente.

Se observa una alta migración de la población joven hacia lugares con mayores oportunidades de empleo, lo que ocasiona el abandono de los pequeños poblados donde hay una enorme cantidad de recursos naturales que se podría aprovechar para impulsar la economía local creando actividades turísticas amigables con el medio ambiente.

El turismo de naturaleza en esta zona podrá ser una alternativa de desarrollo siempre y cuando se implemente un plan de desarrollo local que promueva la conservación de su territorio y su importancia, para frenar futuras invasiones o mal uso de éste.

La falta de infraestructura turística hace que se estanquen las comunidades de la costa de Jalisco que tienen gran potencial para desarrollarse. El mejoramiento de las carreteras es un punto clave para tener una ventaja competitiva, ya que permite aprovechar la cercanía de los destinos ya consolidados como lo es Puerto Vallarta en el norte y el Puerto de Manzanillo en el sur.

Los estudios de prospectiva se utilizan aún de forma muy limitada en Latinoamérica y aún más en México. Es necesario difundir las ventajas de la prospectiva para que se tome conciencia de la necesidad de encontrar soluciones efectivas e integrales que permitan estar a la altura de los crecientes estándares y niveles de competitividad internacional. Lograr niveles de competitividad internacional requiere, necesariamente, la formulación sistemática y organizada de alternativas de desarrollo que provean sentido a la acción colectiva y aglutinen a los actores relevantes para elevar de forma significativa los niveles de productividad y bienestar de la población. Los estudios de futuro ofrecen opciones para enfrentar este desafío, ya que contribuyen a la búsqueda de alternativas concretas en el presente fundamentadas en el pensamiento a largo plazo. Está es una metodología general que puede ser replicada en cualquier territorio tanto de México como del extranjero, analizando las particularidades de cada territorio.

\section{REFERENCIAS BIBLIOGRÁFICAS}

Andrade-Romo, E., Chávez-Dagostino, R. M. y Espinoza-Sánchez, R. (2010). Desarrollo en la región Costa Alegre de Jalisco: el papel del turismo. RESTMA, 11(septiembre), 125-158

Barrera, E. y Muñoz, R. (2003). Manual de turismo rural para micro, pequeños y medianos empresarios rurales. FIDA-PROMER, Argentina.

Bohensky, E. L., Butler, J. R. A., \& Mitchell, D. (2011). Scenarios for Knowledge Integration: Exploring Ecotourism Futures in Milne Bay, Papua New Guinea. Journal of Marine Biology, 2011, 1-11. https://doi.org/10.1155/2011/504651

Cabrera, J. A., Pérez-Martínez, M. y Ribas, P. (2007). Escenarios energéticos. OPTI- IDEA

CCA. (2000). Avances en la promoción del turismo sustentable en áreas naturales protegidas de América del Norte. Nota del Secretariado de la Comisión para la Cooperación Ambiental. Montreal. Canadá. 19 pp. 
Cebrián-Abellán, A. (2008). El Turismo Rural Sostenible, en Cebrián Abellán F. (Coord.): Turismo Rural y Desarrollo Local, (pp. 49-56). Ediciones de la Universidad de Castilla la Mancha.

Cebrián-Abellán, A., Granell-Perez, C., Paunero-Amigó, X. y Ayllón Trujido, T. (2001). La actividad turística patrimonial en la organización del territorio, en Cebrián Abellán, $A$. (Coord.): Turismo cultural y desarrollo sostenible, (pp. 47-70). Análisis de áreas patrimoniales. Universidad de Murcia.

Chávez-Dagostino, R. M., Andrade-Romo, E. y Espinoza-Sánchez, R. (2006). Patrimonio, turismo y desarrollo sustentable: caso costa de Jalisco. Teoría y Praxis, 2, 9-23.

Chávez-Dagostino, R. M., Cifuentes-Lemus, J. L., Andrade, E., Espinoza, R., Massam, B. y Everitt, J. C. (2008). Huellas ecológicas y sustentabilidad en la costa norte de Jalisco, México. Teoría y Praxis, 5, 137-144.

Chávez-Dagostino, R. M., Andrade-Romo, E. y Espinoza-Sánchez, R. (2011). Informe técnico final. Proyecto Impacto del turismo de naturaleza en la costa de Jalisco. UDG 4402009. Guadalajara: Consejo Estatal de Ciencia y Tecnología de Jalisco/Universidad de Guadalajara.

Chávez-Dagostino, R. M., Gómez-Morales, T., Sánchez, R. y Andrade, E. (2012). Notas sobre la sustentabilidad y la responsabilidad social empresarial del turismo de naturaleza en la Costa de Jalisco. Teoría y Praxis, 11, 60-77.

COEPO. (2011). Análisis Sociodemográfico Región 09, Costa Norte 2010, Jalisco. Consejo Estatal de Población. Disponible en http://iieg.gob.mx/contenido/ PoblacionVivienda/09RegionCostaNorte2010.pdf. (17/03/18)

Crosby, A. (1993). El desarrollo turístico sostenible en el medio rural, Madrid, Centro Europeo de Formación Ambiental y Turística, 268 pp. Citado en Cebrián Abellán F. (Coord.): Turismo Rural y Desarrollo Local, (pp. 49-56). Albacete, Ediciones de la Universidad de Castilla la Mancha.

Crosby, A. (1994). Interpretación ambiental y turismo rural. Gobierno de Navarra-Centro Europeo de Formación Ambiental y Turística, Pamplona.

Daltabuit, G. M., Cisneros, L. y Vázquez Santillan, E. (2000). Ecoturismo y desarrollo Sustentable: Impacto en comunidades rurales de la selva maya. Centro Regional de Investigaciones Multidisciplinarias UNAM. México. 357 pp.

Dirección General de Empresa. (2002). El patrimonio natural y cultural como factor de desarrollo del turismo sostenible en los destinos turísticos no tradicionales. Comisión Europea, Unidad de Turismo, Bruselas.

Gobierno del Estado de Jalisco. (2013). Sistema de información Estadística y Geográfica del Estado de Jalisco. Fichas Municipales. Disponible en http://seplan.app.jalisco.gob.mx/ ficha/. (18/03/18)

Godet, M. (2000). La Caja de Herramientas de la Prospectiva Estratégica, 4ạ edición, España. IPAE. (2009). Prospectiva del sector eléctrico 2009-2018. Perú: Centro de Estudios Estratégicos Jouvenel, B. (1964). L'art de la conjeture. Monaco: Futuribles. Éditions du Rocher.

Khoshtaria, T. K., y Chachava, N. T. (2017). Prospects of ecotourism development in recreation areas of South Georgia. Annals of Agrarian Science, 15(3), 312-317. https://doi. org/10.1016/i.aasci.2017.07.004 
Kurt, S. S., Duzgunes, E., Kurdoglu, B. C., y Demirel, O. (2016). Example study about Meryemana Valley (Trabzon / Turkey) for determining the potential campground in the scope of nature. Journal of Environmental Protection and Ecology, 17(2), 576-583.

Lacambra, V. M. (1997) “La valoración del patrimonio natural a través del fomento del turismo. El caso del Somontano de Barbastro". Revista de Desarrollo Local y Cooperativismo Agrario, 1, 301-317.

López Pardo, G. y Palomino Villavicencio, B. (2015). Situación General de las México Indigenous Companies in. TEACS, 7(16), 93-106.

Macedo Ribeiro, E. y Nascimento, E. (2014). Ecotourism in Amazonas: Future Prospects through Senarios. Athens Journal of Tourism, 1(2), 147-158.

Martin, Ben R. (2001). Matching Societal Needs and Technological Capabilities: Research Foresight and the Implications for Social Sciences. SPRU. University of Sussex. Chapter 11 of Social Sciences and Innovation, OECD Proceedings; Paris: 2001, 105-115.

Martínez, P. y López-Prado, A. (2010). Pesca artesanal en la costa de Jalisco. Conflictos en torno a la conservación biocultural. Observatorio del Desarrollo, 2(7). 38-46.

Medina, J. y Ortegón, E. (2006). Manual de prospectiva y decisión estratégica: bases teóricas e instrumentos para América Latina y el Caribe. Instituto Latinoamericano y del Caribe de Planificación Económica y Social (ILPES). Área de Proyectos y Programación de Inversiones. Serie manuales no 51, Santiago de Chile. 438 pp.

Mojica, F. J. (2005). La construcción del futuro: concepto y modelo de la prospectiva estratégica, territorial y tecnológica. Bogotá, Colombia: Universidad del Externado.

Moriarty, J. P. (2012). Theorising scenario analysis to improve future perspective planning in tourism. Journal of Sustainable Tourism. https://doi.org/10.1080/09669582.2012.673 $\underline{619}$

OMT. (2002). Cumbre Mundial del Ecoturismo. Informe final. Quebec, Candada. 148 pp.

Ponce, H. (2007). Matrix SWOT: An alternative for diagnosing. Enseñanza e Investigación en Psicología, 12(1), 113-130.

Ramírez, J. (2004). Futuros diversos: Corazón de la prospectiva. Revista Universidad de Guadalajara. Futuro y Prospectiva, (26). 2002-2003. En: http://www.geocities.ws/ jonelrm/bmk/diecisiete.htm

Riensche, M. (2016). Desarrollo turístico y manejo de ecosistemas en la Costalegre de Jalisco, México. Tesis doctoral. Universidad Nacional Autónoma de México. https://doi. org/10.13140/RG.2.2.13385.75365

Rodríguez, J. (2011). La construcción de la síntesis socioeconómica: Programa Rector del Desarrollo Urbano en Jalisco, México. Architecture, City and Environment, 5, 103-120.

SECTUR (2004). Turismo Alternativo. México. Distrito Federal.

SECTUR (2017). Estrategia para el Impulso y Desarrollo del Turismo de Naturaleza en México. https://www.gob.mx/sectur/es/documentos/estrategia-para-el-impulso-y-desarrollo-del-turismo-de-naturaleza-en-mexico-138341?state=published

SECTUR. (2018a). Resultados de la Actividad Turística (Vol. Enero). Ciudad de México.

SECTUR. (2018b). Vision Global del Turismo a Mexico. Retrieved from http://www.datatur. sectur.gob.mx/Documentos compartidos/VisionGlobalTurismoAMexAbr2018.pdf

Secturjal. (2017). Estadistica del sector turístico 2016. Retrieved September 29, 2018, from https://secturjal.jalisco.gob.mx/invierte-en-jalisco/estadisticas 
Steiner, G. A. (1998). Planeación estratégica, 23a. Reimpresión, Cecsa, México, 366 pp.

Tello Díaz, C. (2014). La colonización de la costa de Jalisco: 1953-1959. Relaciones, 35(140), 267-293.

Wearing, S. y Neil, J. (2009). Ecotourism: Impacts, Potentials and Possibilities. ButterworthHeinemann, Routledge: Oxford. 